\title{
The Silent Physician
}

\author{
Hemal K. Kanzaria, $M D^{7}$ and Robert H. Brook, MD, ScD ${ }^{2}$ \\ 'Robert Wood Johnson Clinical Scholars Program, Department of Emergency Medicine, University of California Los Angeles, Los Angeles, CA, \\ USA; ${ }^{2}$ RAND Corporation, David Geffen School of Medicine, University of California Los Angeles, Los Angeles, CA, USA.
}

J Gen Intern Med 28(11):1389-91

DOI: $10.1007 / \mathrm{s} 11606-013-2525-y$

(c) Society of General Internal Medicine 2013

I $\mathrm{n}$ just a few months, the US health care system will change dramatically. About 16 million Americans will be newly enrolled in Medicaid, and health care coverage will be provided to over half of those previously uninsured. ${ }^{1}$ Accountable care organizations, highlighted in the Patient Protection and Affordable Care Act (ACA) as key to improving quality and containing costs, now number in the hundreds. Electronic medical records are widespread, if not yet commonplace. Some view these changes as precipitous; others view them as long overdue. But there's no doubt that change is in the air. What does the average physician think about these evolving trends and his or her participation in them? We have no idea.

There are currently more than 750,000 practicing physicians in the United States. ${ }^{2}$ However, except for a few leaders numbering perhaps in the hundreds, physicians are generally silent about the future environment in which they will be practicing and about the role they aspire to play in it. If we knew their views, could we bring about the changes being called for - increased access, increased health, lower costs - in a manner that produces less short-term harm and disruption?

The health services research community has produced an enormous body of work suggesting that both substantial overuse and underuse of care exist in our current system. As much as one-third of all care may actually produce more harm than good - or at best, be equivocal. ${ }^{3}$ At the same time, the average patient going to see an average physician in the outpatient setting receives only about $55 \%$ of the services that are required if high quality care were to be provided. ${ }^{4}$

Unfortunately, no one knows whether practicing physicians have even read this body of work. Do they disagree or agree with the above conclusions? Do they believe that these conclusions apply to their own practice, or that of their colleagues? Would physicians be willing to simultaneously reduce both under-use and over-use if they received more aligned support from health insurance companies, the government, and the public? What should that support be? Since efforts to increase the value obtained from the health care system must ultimately be led by, or at least facilitated by physicians, having answers to these questions is essential.

Published online June 28, 2013
Would the answers differ substantially by a physician's specialty or age? It is often assumed that younger physicians might be more willing to change or are more knowledgeable about deficiencies in care. However, there is no evidence to support such assertions, because nobody has asked physicians what they believe, or how they would like to see change come about.

Another example relates to the training or education needed to perform certain tasks. When a student decided to become a gastroenterologist, did he or she know that a substantial part of professional life would be spent doing screening colonoscopies? Did aspiring ophthalmologists, radiologists, dermatologists, or primary care physicians know that they would spend most of their time performing routine cataract operations, reading screening mammograms, treating uncomplicated acne, or counseling patients about wellness? Do these physicians believe that 7-10 years of post-college education are needed to acquire the skills necessary for such work? Or do they believe that a computer can be trained to read the mammogram, and a high-school graduate with excellent fine motor skills could be quickly taught to perform the above procedures in a more careful and reliable manner than they are currently performed? Do physicians realize or believe that as technology improves, the need for highly educated people to perform such tasks decreases? Do they feel the expanding role of technology, or of alternative provider options, is appropriate? Do they perceive that such added services improve patient care, or enhance the care that they themselves are able to deliver?

Similarly, consider the concept of an accountable care organization, where a group of providers are jointly responsible for the quality and cost of care provided to a defined population. Currently, most physicians are trained to dedicate most of their time and attention to the patient sitting in front of them. Moreover, few physicians have systems that track what happens to patients over time, and even fewer physicians use such information to proactively manage their patients. What do physicians think about being more responsible for care delivered to a population of patients? How will they help control costs while also caring for the millions more that will soon gain access to insurance and care? How will these changes influence their practice of medicine?

Relative to technological advances, one could argue that the way physicians practice has not changed substantially. However, the Internet and social media are fundamentally changing every human behavior from dating to learning to clinical care. 
Patients commonly use the Internet to educate themselves about health issues, and may even write public reviews of their physicians on popular websites such as Yelp. Many health systems offer patients reliable, if not immediate, electronic access to their physician. How do physicians view such changes? What advice could they lend to better optimize this boom in health information technology?

The question is where are the hearts and minds of physicians today? How compatible are physician views with the monumental changes that are occurring in society - changes that will inevitably, and dramatically, affect the medical profession and how care is delivered? How would physicians like to see medicine change? What barriers need to be reduced? How can physicians partner with patients to improve population health at an affordable cost?

Attempts to answer this barrage of questions have largely been limited to physician surveys conducted by consulting firms. ${ }^{5}$ These unfortunately often omit even a basic description of the survey methodology undertaken and suffer dismal response rates of 2-3\%. Physician organizations such as the American Medical Association (AMA), the American College of Physicians (ACP), and the Society for General Internal Medicine (SGIM) can and should play a larger role in eliciting physician viewpoints from their membership in response to such questions. Such organizations are formed, in part, to represent their members' voice, and already have a recognized role in the national debate on health care reform. However, it remains unclear if the average physician member in such organizations is being activated to share their own opinions to help inform the debate, or if there is a disconnect between organization leadership and its membership.

Those pushing for change may not understand the perspectives and visions of average physicians - arguably, the gateway to effective change. What needs to be done to engage physicians as allies in the change process? How can the education of young physicians be approached to give them the skills they need to deliver high-quality affordable care in a world of medical homes, accountable care organizations, evidence-based medicine, and metaanalyses?

Despite the potential limitations of survey research and opinion polling, such methodology may be the most efficient manner to engage physicians collectively. If done correctly, both could be achieved effectively through physician organizations. For example, the American College of Emergency Physicians (ACEP) recently formed the Emergency Medicine Practice Research Network (EMPRN) specifically to amplify their physician-members' voice. $^{6} \mathrm{~A}$ representative sample of over 1,200 emergency physicians have agreed to participate in 3-4 surveys per year to inform the organization's efforts surrounding advocacy and clinical practice. Many other physician organizations and health systems may have similar efforts, but to obtain useful information, such work must be done in a robust manner with validly constructed survey tools and high response rates. Health service researchers thus also have a role to play. In the past, nationally representative physician surveys using rigorously developed instruments have been undertaken to inform important areas of health care reform. ${ }^{7}$ An alternative approach that may be equally effective in answering such questions is opinion polling of physicians. This is routinely and efficiently done in gathering public opinion on health care reform. ${ }^{8}$ Through such attempts to gather the physician voice, we may find that physicians are not of one mind on many issues related to health care reform. However, encouraging this discourse is the first step of involving physicians.

Can we really fundamentally transform the health system without engaging the average physician in a conversation that changes their silence to debate? Understanding what physicians feel, what they understand, and what they need, and knowing how to communicate to them the urgency of change are vital if delivery systems are to improve dramatically. Physicians cannot be silent anymore. In training to become a doctor, physicians learn to ask open-ended questions, to listen actively, and to respond with an assessment and plan. After listening to policymakers and leaders of professional societies, what does the typical physician think? Do they believe Choosing Wisely has nothing to do with them? Do they believe that they can improve the value of health care? Having no voice means having no say, and having no say will be detrimental for the future of American medicine, and for the health of Americans.

Acknowledgements: We thank Alissa Detz, MD for her careful review of early drafts of this manuscript.

Conflict of Interest: The authors declare that they do not have any conflicts of interest.

Corresponding Author: Hemal K. Kanzaria, MD; Robert Wood Johnson Clinical Scholars Program, Department of Emergency Medicine, University of California Los Angeles, 10940 Wilshire Blvd., Suite 710, Los Angeles, CA, USA (e-mail: hkanzaria@mednet.ucla.edu).

\section{REFERENCES}

1. Kaiser Family Foundation. http://www.kff.org/healthreform/upload/ 8288.pdf and http://facts.kff.org/jama_082212. Accessed June 2013.

2. National Center for Health Statistics. Health, United States, 2011. http:// www.cdc.gov/nchs/data/hus/hus11.pdf - 110. Accessed June 2013

3. Berwick DM, Hackbarth AD. Eliminating waste in US health care. JAMA. 2012;307(14):1513-1516.

4. McGlynn EA, Asch SM, Adams J, et al. The quality of health care delivered to adults in the United States. N Engl J Med. 2003;348(26):2635-2645. 
5. The Physicians Foundation: Health Reform and the Decline of Physician Private Practice. http://www.physiciansfoundation.org/uploads/default/ Health_Reform_and_the_Decline_of_Physician_Private_Practice.pdf. Accessed June, 2013.

6. Schneider S, Sklar D. EMPRN: Research network amplifies physician voices. ACEP News. 1/17/2013.
7. McCormick D, Woolhandler S, Bose-Kolanu A, Germann A, Bor DH, Himmelstein DU. U.S. physicians' views on financing options to expand health insurance coverage: a national survey. J Gen Intern Med. Apr 2009;24(4):526-531.

8. Blendon RJ, Benson JM. Public opinion at the time of the vote on health care reform. N Engl J Med. 2010;362(16):e55. 